\title{
Willingness of medical students to be examined in a physical examination course
}

\author{
Manuel Burggraf ${ }^{1 *}$ D, Julia Kristin², Alexander Wegner', Sascha Beck', Stephanie Herbstreit', Marcel Dudda', \\ Marcus Jäger ${ }^{1}$ and Max Daniel Kauther ${ }^{1}$
}

\begin{abstract}
Background: Physical examination courses are an essential part of the education of medical students. The aim of this study was to ascertain the factors influencing students' motivation and willingness to participate in a physical examination course.

Methods: Students were asked to complete a questionnaire subdivided into five domains: anthropometric data, religiousness, motivation to take part in physical examination courses, willingness to be physically examined at 11 different body regions by peers or a professional tutor and a field for free text.

Results: The questionnaire was completed by 142 medical students. The importance of the examination course was rated 8.7 / 10 points, the score for students' motivation was 7.8 / 10 points. Willingness to be physically examined ranged from 6 to 100\% depending on body part and examiner. Female students were significantly less willing to be examined at sensitive body parts (breast, upper body, groin and the hip joint; $p=.003$ to <.001), depending on group composition and / or examiner. Strictly religious students showed significantly less willingness to undergo examination of any part of the body except the hand $(p=.02$ to $<.001)$. Considering BMI, willingness to be examined showed comparable rates for normal weight and under- / overweight students in general (80\% vs. 77\%). Concerning the composition of the group for physical examination skills courses, students preferred selfassembled over mixed gender and same gender groups.

Conclusions: Peer physical examination is a method to improve students' skills. While motivation to participate in and acceptance of the physical examination course appears to be high, willingness to be examined is low for certain parts of the body, e.g. breast and groin, depending on religiousness, gender and examiner. Examination by a professional medical tutor did not lead to higher acceptance. Most students would prefer to choose their team for physical examination courses themselves rather than be assigned to a group.
\end{abstract}

Keywords: Physical examination, Clinical skills, Teaching, Medical students, Peer, Medical education

\section{Background}

Despite technical and medical advances and E-health, the basic physical examination of patients is still a mandatory competence for every physician. Acquired physical examination skills are known to be of lasting value. Data suggests that even greater emphasis should be placed on basic clinical skills $[1,2]$. In recent years, there has been a trend in medical curricula away from classical teacher-centred lectures towards clinical skills

\footnotetext{
*Correspondence: manuel.burggraf@uk-essen.de

${ }^{1}$ Department of Orthopaedics and Trauma Surgery, University Hospital Essen, University of Duisburg-Essen, Hufelandstr. 55, 45147 Essen, Germany Full list of author information is available at the end of the article
}

courses including peer physical examinations by students as well as bedside teaching. All this attention has encouraged many medical schools to revise their curricula and emphasize the importance of teaching more clinical skills and to establish clinical skill centres to provide appropriate training [3-5]. Consequently, objective structured clinical examinations (OSCEs) and mini-clinical evaluation exercises (mini-CEXs) are additionally used as assessment methods $[6,7]$ to grade the clinical skills of students.

At some teaching hospitals standardised patients are used in medical education to expose students to clinical contexts and facilitate transition to clinical practice. The main limiting factors are costs and availability, not only

(c) The Author(s). 2018 Open Access This article is distributed under the terms of the Creative Commons Attribution 4.0 International License (http://creativecommons.org/licenses/by/4.0/), which permits unrestricted use, distribution, and reproduction in any medium, provided you give appropriate credit to the original author(s) and the source, provide a link to the Creative Commons license, and indicate if changes were made. The Creative Commons Public Domain Dedication waiver (http://creativecommons.org/publicdomain/zero/1.0/) applies to the data made available in this article, unless otherwise stated. 
in countries with public universities in which medical training is free of charge. Hence, the physical examination of real patients without prior teaching can be very challenging for both students and patients [8]. The top three most relevant aspects of pre-clinical preparation for clinical practice are skills training, clinical tutorials with real patients and standardised patients contacts [8]. Mounsey et al. showed that standardised patient role-plays are similar in effectiveness to student role-plays when teaching basic motivational interviewing skills [9].

Peer physical examination is as an experiential method of learning clinical skills where medical students are models for one another [10]. It stands for a teaching method in a supervised environment, including a constructive feedback from tutors, that allows to develop compassion and empathy, to improve communication skills and to gain insight the patient's psychosocial experiences from being examined [11]. Mentioned negative aspects for students are the perceived pressure to act as model (male > female), the missing possibility for the model to participate in examining and the lack of abnormal signs on students [11]. Student's gender, the examination of specific, sensitive body regions, religion and ethnicity appear to be potential barriers to some students willingness to participate in PPE [12]. Therefore, the principle of non-maleficence, physically and emotionally through embarrassment or harassment, must be maintained. It is suggested to provide written protocols available to students before classes, information sheets stating the risks and benefits, and to obtain written informed consent from students $[10,13,14]$.

Evaluation of student participants is an important resource for implementation and continuous improvement of training programs. The aim of this study was to analyse the motivation and willingness of students to be examined for teaching purposes and to identify potential problem areas in this context. The results might then provide a basis for improvement of the physical examination courses of our and other institutions.

\section{Methods}

Ethical considerations: The study was approved by the local ethics committee of the University Hospital Essen (study number: 11-4891-BO).

Participants and setting: Third-year medical students (first year in clinical training) of the Faculty of Medicine of the University of Duisburg-Essen at the University Hospital of Essen (Germany), who were about to attend the mandatory peer examination course, were queried. The interdisciplinary course, carried out through various clinical departments, is conducted in small groups and supervised by a professional tutor. Following the mandatory introductory lecture, students were asked to complete a questionnaire about peer examination courses.
All of them were of legal age, participated on a voluntary basis and provided written informed consent. They completed a written questionnaire about peer physical examinations in clinical skills courses. Questionnaires lacking information on gender or students who refused participation were excluded. All data was collected in anonymised form.

Questionnaire: We designed a self-administered questionnaire, subdivided into five domains, to document anthropometric and personal data comprising age, gender, height, weight and religious affiliation. Using a 10-point Likert-scale, respondents indicated the importance for them and their motivation in participating $(1=$ not at all, to $10=$ very important and highest motivation, respectively) in the physical examination skills course. Furthermore, the frequency of voluntary participation in physical examination by a tutor in front of a group of students was also recorded. The core element of the questionnaire was the potential willingness to be examined on 11 different body parts by a same gender student, a different gender student, a same gender professional tutor or a different gender professional tutor. The body regions comprised head and neck, hand, arm and shoulder, upper body, breast, abdomen, back, groin, lower leg and foot, knee and the hip joint. Additionally, students were asked for their preferred composition of the group: self-assembled, mixed gender or same gender. Finally, students could write a free text suggestion as to how physical examination skills could be improved.

Groups of students were formed according to gender, body mass index (BMI) and religiousness. Normal weight was defined as a BMI of 18.5 to 25 , underweight as a BMI of $<18.5$ and overweight as a $\mathrm{BMI}>25$, respectively.

Pearson's chi-squared test $\left(\chi^{2}\right)$ was used to analyse the influence of gender, BMI and religiousness. A $p$-value $<.05$ (2-sided) was considered statistically significant. Additionally, the mean square contingency coefficient (phi coefficient, $\phi$ ) was computed to give the strength of association. The statistical analysis was performed using $\mathrm{IBM}^{\circ}$ SPSS Statistics 25.

\section{Results}

All (145/145) recruited students filled in the questionnaire. The final study included 142 of 145 completed questionnaires. Three questionnaires were excluded due to missing information regarding gender (Table 1).

Some respondents did not comment on certain subdomains: age and height: $1 \mathrm{~m}$, weight: $1 \mathrm{~m}$ and $6 f$, religious affiliation: $1 m$ and $1 f$, degree of religiousness: $10 m$ and $22 f$.

The importance of the physical examination course was rated 8.7 out of 10 points $(m=8.6 ; f=8.7)$, the score for students' motivation was 7.8 points $(m=7.6 ; f=7.9)$. Fifteen of sixty males (25\%) and 26 of 82 females $(32 \%)$ never made themselves available for physical examination by a medical tutor, 41 males $(68 \%)$ and 46 females 
Table 1 Anthropometric data

\begin{tabular}{lll}
\hline & Male students & Female students \\
\hline Participants ( $n=142)$ & $n=60$ (42\%) & $n=82$ (58\%) \\
Age: 19-52 years & $\begin{array}{l}24 \text { (mean) / 23 } \\
\text { (median) }\end{array}$ & $\begin{array}{l}23 \text { (mean) / } 22 \\
\text { (median) }\end{array}$ \\
Height & $1.82 \mathrm{~m}$ & $1.69 \mathrm{~m}$ \\
Weight & $79.9 \mathrm{~kg}$ & $60.8 \mathrm{~kg}$ \\
BMI (both & 24.1 & 21.2 \\
gender:22.5) & & \\
Normal BMl & $n=105$ (male + female) \\
BMl < 18.5 or $>25$ & $n=30$ (male + female) \\
Religion & 49 Christian & 65 Christian \\
& 1 Muslim & 8 Muslim \\
& 2 other & 4 other \\
& 7 no religious & 4 no religious \\
affiliation & affiliation \\
Strength of & 3 strong belief & 9 strong belief \\
religiousness & 47 less religious & 51 less religious \\
\hline
\end{tabular}

(56\%) up to five times. Four males (7\%) and 9 females (11\%) were examined more than five times by a medical tutor.

In general, willingness to be physically examined by peers is higher in male than in female students $(86 \%$ vs. 74\%; see Table 2).

Nevertheless, both genders preferred to be examined by a peer of the same gender (males 90\%; females 86\%), whereas willingness to be physically examined by a tutor of the opposite gender was least acceptable (males 83\%; females 66\%). In fact, the reported willingness strongly depends on the body region to be examined (see Table 3).

Willingness to be examined ranged from 6\% (breast examination of females by a different gender tutor) to $100 \%$ (examination of the hand of females by a same gender student). Examination of the head and neck as well as the hand was consistently accepted by $>90 \%$ of the students, irrespective of the examiner. One male student stated no potential willingness to be physically examined at all, irrespective of body region and examiner.

Statistical analysis showed that female students are significantly less willing to undergo breast examination $(p<.001$; $\phi 0.50$ to 0.75 ), which is irrespective of the examiner (see Table 4).

Table 2 Reported willingness of students to be examined depending on examiner and gender

\begin{tabular}{lll}
\hline & Male students & Female students \\
\hline Overall & $86 \%$ & $74 \%$ \\
Student of same gender & $90 \%$ & $84 \%$ \\
Student of different gender & $87 \%$ & $70 \%$ \\
Tutor of same gender & $83 \%$ & $76 \%$ \\
Tutor of different gender & $83 \%$ & $66 \%$ \\
\hline
\end{tabular}

Furthermore, in contrast to male students, female students are significantly less willing to be examined by a student or a tutor of the opposite gender at the upper body, the groin and the hip joint $(p=.003$ to $<.001 ; \phi$ 0.25 to 0.34 ). In fact, males also stated the least willingness $(55 \%$ to $62 \%)$ to be examined on the groin under any constellation.

Considering BMI, willingness to be examined showed comparable rates for normal weight and under- / overweight students in general ( $80 \%$ vs. $77 \%)$ and irrespective of examiner (see Table 5).

A statistically significantly higher willingness of normal weight students was only found for the examination of the arm and shoulder region by a same gender student $(p=.04 ; \phi 0.18)$ (see Table 6).

Regarding the influence of religiousness, 12 students stated that they were strictly religious (Muslims, Christians and others). The 12 students with strong religious beliefs showed an overall willingness of $52 \%$ to be examined. Compared to students who reported a minor degree of religiousness, the strictly religious students showed significantly less willingness to undergo examination of any part of the body except the hand (see Table 7).

This finding is almost irrespective of the examiner.

Concerning the composition of the group for physical examination skills courses, students preferred self-assembled (males 62\%; females 73\%) over mixed gender (males 38\%; females $21 \%$ ) and same gender groups (males 5\%; females $9 \%$ with multiple answers allowed).

In the free text answer section students could state their expectations and their fears. They pointed out that small groups, a short revision of the most important theoretical knowledge at the beginning, a well-prepared tutor, and structured feedback from the tutor provide the basis for a good examination skills course. Being examined by another person made them aware of how a patient feels. They recognise the benefit of learning these skills in a "safe" environment before being in contact with real patients. Nevertheless, the intimidating, and for some students embarrassing act of taking one's clothes off in front of fellow students seems to have negative connotations.

\section{Discussion}

This study elucidates the influence of not only assumable confounders such as gender and weight but also the role of religiousness in peer examination. Limitations of the study are its study design without information on longitudinal changes in the attitude of students towards peer examination and a small subgroup size of strongly religious students. Furthermore, as this study is strictly exploratory, a correction for multiple testing was not performed.

Intimate body regions are the breasts of females, genitals (including the pelvic organs and inguinal region) and the 
Table 3 Reported willingness to be examined on different body regions according to group composition and gender

\begin{tabular}{|c|c|c|c|c|c|c|c|c|}
\hline \multirow[t]{2}{*}{ Gender } & \multicolumn{2}{|c|}{ Same gender student } & \multicolumn{2}{|c|}{ Different gender student } & \multicolumn{2}{|c|}{ Same gender tutor } & \multicolumn{2}{|c|}{ Different gender tutor } \\
\hline & Male & Female & Male & Female & Male & Female & Male & Female \\
\hline Head and neck & $98 \%$ & $98 \%$ & $97 \%$ & $93 \%$ & $93 \%$ & $95 \%$ & $92 \%$ & $90 \%$ \\
\hline Hand & $98 \%$ & $100 \%$ & $98 \%$ & $99 \%$ & $93 \%$ & $99 \%$ & $92 \%$ & $96 \%$ \\
\hline Arm and shoulder & $97 \%$ & $96 \%$ & $95 \%$ & $93 \%$ & $93 \%$ & $93 \%$ & $90 \%$ & $89 \%$ \\
\hline Upper body & $90 \%$ & $81 \%$ & $85 \%$ & $60 \%$ & $80 \%$ & $68 \%$ & $80 \%$ & $46 \%$ \\
\hline Breast & $88 \%$ & $39 \%$ & $82 \%$ & $7 \%$ & $75 \%$ & $24 \%$ & $75 \%$ & $6 \%$ \\
\hline Abdomen & $92 \%$ & $88 \%$ & $85 \%$ & $77 \%$ & $80 \%$ & $83 \%$ & $80 \%$ & $72 \%$ \\
\hline Back & $92 \%$ & $89 \%$ & $85 \%$ & $81 \%$ & $83 \%$ & $84 \%$ & $82 \%$ & $76 \%$ \\
\hline Groin & $62 \%$ & $61 \%$ & $55 \%$ & $29 \%$ & $57 \%$ & $43 \%$ & $57 \%$ & $23 \%$ \\
\hline Lower leg and foot & $92 \%$ & $93 \%$ & $90 \%$ & $85 \%$ & $87 \%$ & $84 \%$ & $88 \%$ & $81 \%$ \\
\hline Knee & $97 \%$ & $96 \%$ & $95 \%$ & $90 \%$ & $93 \%$ & $94 \%$ & $93 \%$ & $87 \%$ \\
\hline Hip joint & $85 \%$ & $79 \%$ & $87 \%$ & $61 \%$ & $82 \%$ & $71 \%$ & $83 \%$ & $60 \%$ \\
\hline
\end{tabular}

Table 4 Differences in willingness to be examined between male and female students

\begin{tabular}{|c|c|c|c|c|}
\hline Gender & Same gender student & Different gender student & Same gender tutor & Different gender tutor \\
\hline Head and neck & $\begin{array}{l}x^{2}[1]=0.10 \\
p=.75 \\
\varphi=0.03\end{array}$ & $\begin{array}{l}x^{2}[1]=1.03 \\
p=.31 \\
\varphi=0.09\end{array}$ & $\begin{array}{l}x^{2}[1]=0.21 \\
p=.65 \\
\varphi=0.04\end{array}$ & $\begin{array}{l}x^{2}[1]=0.08 \\
p=.77 \\
\varphi=0.02\end{array}$ \\
\hline Hand & $\begin{array}{l}x^{2}[1]=1.38 \\
p=.24 \\
\varphi=0.10\end{array}$ & $\begin{array}{l}x^{2}[1]=0.05 \\
p=.82 \\
\varphi=0.02\end{array}$ & $\begin{array}{l}x^{2}[1]=3.03 \\
p=.08 \\
\varphi=0.15\end{array}$ & $\begin{array}{l}x^{2}[1]=1.42 \\
p=.23 \\
\varphi=0.10\end{array}$ \\
\hline Arm and shoulder & $\begin{array}{l}x^{2}[1]=0.01 \\
p=.92 \\
\varphi=0.01\end{array}$ & $\begin{array}{l}x^{2}[1]=0.31 \\
p=.58 \\
\varphi=0.05\end{array}$ & $\begin{array}{l}x^{2}[1]=0.02 \\
p=.88 \\
\varphi=0.01\end{array}$ & $\begin{array}{l}x^{2}[1]=0.04 \\
p=.85 \\
\varphi=0.02\end{array}$ \\
\hline Upper body & $\begin{array}{l}x^{2}[1]=2.39 \\
p=.12 \\
\varphi=0.13\end{array}$ & $\begin{array}{l}x^{2(1)}=10.60 \\
p=.001 \\
\varphi=0.27\end{array}$ & $\begin{array}{l}x^{2}[1]=2.42 \\
p=.12 \\
\varphi=0.13\end{array}$ & $\begin{array}{l}\mathrm{X}^{2(1)}=16.44 \\
p<.001 \\
\varphi=0.34\end{array}$ \\
\hline Breast & $\begin{array}{l}\mathrm{X}^{2(1)}=35.06 \\
p<.001 \\
\varphi=0.50\end{array}$ & $\begin{array}{l}x^{2(1)}=80.71 \\
p<.001 \\
\varphi=0.75\end{array}$ & $\begin{array}{l}\mathrm{X}^{2(1)}=35.75 \\
p<.001 \\
\varphi=0.50\end{array}$ & $\begin{array}{l}\mathrm{X}^{2(1)}=72.11 \\
p<.001 \\
\varphi=0.71\end{array}$ \\
\hline Abdomen & $\begin{array}{l}x^{2}[1]=0.55 \\
p=.46 \\
\varphi=0.06\end{array}$ & $\begin{array}{l}x^{2}[1]=1.46 \\
p=.23 \\
\varphi=0.10\end{array}$ & $\begin{array}{l}x^{2}[1]=0.20 \\
p=.66 \\
\varphi=0.04\end{array}$ & $\begin{array}{l}x^{2}[1]=1.21 \\
p=.27 \\
\varphi=0.09\end{array}$ \\
\hline Back & $\begin{array}{l}x^{2}[1]=0.27 \\
p=.60 \\
\varphi=0.04\end{array}$ & $\begin{array}{l}x^{2}[1]=0.49 \\
p=.49 \\
\varphi=0.06\end{array}$ & $\begin{array}{l}x^{2}[1]=0.02 \\
p=.90 \\
\varphi=0.01\end{array}$ & $\begin{array}{l}x^{2}[1]=0.75 \\
p=.39 \\
\varphi=0.07\end{array}$ \\
\hline Groin & $\begin{array}{l}x^{2}[1]=0.01 \\
p=.93 \\
\varphi=0.01\end{array}$ & $\begin{array}{l}\mathrm{x}^{2(1)}=9.55 \\
p=.002 \\
\varphi=0.26\end{array}$ & $\begin{array}{l}x^{2}[1]=2.71 \\
p=.10 \\
\varphi=0.14\end{array}$ & $\begin{array}{l}\mathrm{X}^{2(1)}=16.62 \\
p<.001 \\
\varphi=0.34\end{array}$ \\
\hline Lower leg and foot & $\begin{array}{l}x^{2}[1]=0.05 \\
p=.82 \\
\varphi=0.02\end{array}$ & $\begin{array}{l}x^{2}[1]=0.67 \\
p=.41 \\
\varphi=0.07\end{array}$ & $\begin{array}{l}x^{2}[1]=0.06 \\
p=.80 \\
\varphi=0.02\end{array}$ & $\begin{array}{l}x^{2}[1]=1.57 \\
p=.21 \\
\varphi=0.11\end{array}$ \\
\hline Knee & $\begin{array}{l}x^{2}[1]=0.01 \\
p=.92 \\
\varphi=0.01\end{array}$ & $\begin{array}{l}x^{2}[1]=1.10 \\
p=.30 \\
\varphi=0.09\end{array}$ & $\begin{array}{l}x^{2}[1]=0.02 \\
p=.89 \\
\varphi=0.01\end{array}$ & $\begin{array}{l}x^{2}[1]=1.24 \\
p=.27 \\
\varphi=0.09\end{array}$ \\
\hline Hip joint & $\begin{array}{l}x^{2}[1]=0.76 \\
p=.38 \\
\varphi=0.07\end{array}$ & $\begin{array}{l}\mathrm{X}^{2(1)}=11.30 \\
p=.001 \\
\varphi=0.28\end{array}$ & $\begin{array}{l}x^{2}[1]=2.23 \\
p=.14 \\
\varphi=0.13\end{array}$ & $\begin{array}{l}\mathrm{x}^{2(1)}=9.12 \\
p=.003 \\
\varphi=0.25\end{array}$ \\
\hline
\end{tabular}


Table 5 Willingness to be examined depending on examiner and body mass index

\begin{tabular}{lll}
\hline & Normal weight & Under-/overweight \\
\hline Overall & $80 \%$ & $77 \%$ \\
Student of same gender & $88 \%$ & $85 \%$ \\
Student of different gender & $79 \%$ & $74 \%$ \\
Tutor of same gender & $80 \%$ & $78 \%$ \\
Tutor of different gender & $74 \%$ & $72 \%$ \\
\hline
\end{tabular}

anus [15]. We also identified the breast and the groin as the most "socially sensitive" body parts, examination of which is unacceptable for a relevant number of students. Our questionnaire did not include the anus or the genitals, as these body regions are not part of the regular physical examination skills course, neither at our nor other German medical institutions. Rees et al. asked for the willingness to examine or be examined by a same gender or opposite gender peer on 12 different body regions (including genitals) [16]. In comparison, we also found that males are more willing than females to be peer examined. We can confirm, that the critical body regions for same gender peer examination comprise the breast, groin and hip, and additionally the upper body and the abdomen in the case of an opposite gender examiner. Our results also confirm the high level of student acceptance of $>95 \%$ for the head and neck, hand, arm and shoulder as well as knee examinations in the case of same gender peer examination as reported in previous studies $[17,18]$. A religious background with strong beliefs still seems to lead to a lower willingness to be examined [19]. Students stated that this has to be respected but, despite this fact, everybody should take part in the examination courses. As do Rees et al., we see that religiousness plays an important role $[17,18]$. In our study, religiousness was an important factor which influenced a student's willingness to actively participate in the examination skills course. Strictly religious students were less willing to be examined even on otherwise uncritical body regions. Furthermore, this finding is independent of the examiner's gender and professional status. Additionally, it should be remembered that in some

Table 6 Differences between normal and under-/overweight students in willingness to be examined

\begin{tabular}{|c|c|c|c|c|}
\hline $\mathrm{BMI}$ & Same gender student & Different gender student & Same gender tutor & Different gender tuto \\
\hline Head and neck & $\begin{array}{l}x^{2}[1]=0.21 \\
p=.65 \\
\varphi=0.04\end{array}$ & $\begin{array}{l}x^{2}[1]=0.48 \\
p=.49 \\
\varphi=0.06\end{array}$ & $\begin{array}{l}x^{2}[1]=0.16 \\
p=.69 \\
\varphi=0.04\end{array}$ & $\begin{array}{l}x^{2}[1]=0.12 \\
p=.73 \\
\varphi=0.03\end{array}$ \\
\hline Hand & $\begin{array}{l}x^{2}[1]=3.49 \\
p=.06 \\
\varphi=0.16\end{array}$ & $\begin{array}{l}x^{2}[1]=0.89 \\
p=.35 \\
\varphi=0.08\end{array}$ & $\begin{array}{l}x^{2}[1]=0.93 \\
p=.34 \\
\varphi=0.08\end{array}$ & $\begin{array}{l}x^{2}[1]=0.16 \\
p=.69 \\
\varphi=0.04\end{array}$ \\
\hline Arm and Shoulder & $\begin{array}{l}\mathrm{x}^{2(1)}=4.23 \\
p=.04 \\
\varphi=0.18\end{array}$ & $\begin{array}{l}x^{2}[1]=0.67 \\
p=.42 \\
\varphi=0.07\end{array}$ & $\begin{array}{l}x^{2}[1]=1.93 \\
p=.17 \\
\varphi=0.12\end{array}$ & $\begin{array}{l}x^{2}[1]=1.59 \\
p=.21 \\
\varphi=0.11\end{array}$ \\
\hline Upper body & $\begin{array}{l}x^{2}[1]=1.07 \\
p=.30 \\
\varphi=0.09\end{array}$ & $\begin{array}{l}x^{2}[1]=0.86 \\
p=.35 \\
\varphi=0.08\end{array}$ & $\begin{array}{l}x^{2}[1]=1.04 \\
p=.31 \\
\varphi=0.09\end{array}$ & $\begin{array}{l}x^{2}[1]=0.33 \\
p=.56 \\
\varphi=0.05\end{array}$ \\
\hline Breast & $\begin{array}{l}x^{2}[1]=0.26 \\
p=.61 \\
\varphi=0.04\end{array}$ & $\begin{array}{l}x^{2}[1]=0.00 \\
p=.97 \\
\varphi=0.00\end{array}$ & $\begin{array}{l}x^{2}[1]=1.45 \\
p=.23 \\
\varphi=0.10\end{array}$ & $\begin{array}{l}x^{2}[1]=0.76 \\
p=.38 \\
\varphi=0.08\end{array}$ \\
\hline Abdomen & $\begin{array}{l}x^{2}[1]=0.41 \\
p=.52 \\
\varphi=0.06\end{array}$ & $\begin{array}{l}x^{2}[1]=2.02 \\
p=.16 \\
\varphi=0.12\end{array}$ & $\begin{array}{l}x^{2}[1]=0.12 \\
p=.74 \\
\varphi=0.03\end{array}$ & $\begin{array}{l}x^{2}[1]=1.03 \\
p=.31 \\
\varphi=0.09\end{array}$ \\
\hline Back & $\begin{array}{l}x^{2}[1]=0.05 \\
p=.82 \\
\varphi=0.02\end{array}$ & $\begin{array}{l}x^{2}[1]=1.04 \\
p=.31 \\
\varphi=0.09\end{array}$ & $\begin{array}{l}x^{2}[1]=0.55 \\
p=.46 \\
\varphi=0.06\end{array}$ & $\begin{array}{l}x^{2}[1]=0.58 \\
p=.49 \\
\varphi=0.07\end{array}$ \\
\hline Groin & $\begin{array}{l}x^{2}[1]=0.26 \\
p=.61 \\
\varphi=0.04\end{array}$ & $\begin{array}{l}x^{2}[1]=0.55 \\
p=.46 \\
\varphi=0.06\end{array}$ & $\begin{array}{l}x^{2}[1]=0.17 \\
p=.68 \\
\varphi=0.04\end{array}$ & $\begin{array}{l}x^{2}[1]=0.02 \\
p=.88 \\
\varphi=0.01\end{array}$ \\
\hline Lower leg and foot & $\begin{array}{l}X^{2}[1]=0.67 \\
p=.42 \\
\varphi=0.07\end{array}$ & $\begin{array}{l}x^{2}[1]=0.07 \\
p=.79 \\
\varphi=0.02\end{array}$ & $\begin{array}{l}x^{2}[1]=0.33 \\
p=.57 \\
\varphi=0.05\end{array}$ & $\begin{array}{l}x^{2}[1]=0.55 \\
p=.46 \\
\varphi=0.06\end{array}$ \\
\hline Knee & $\begin{array}{l}x^{2}[1]=0.93 \\
p=.34 \\
\varphi=0.08\end{array}$ & $\begin{array}{l}x^{2}[1]=0.17 \\
p=.69 \\
\varphi=0.04\end{array}$ & $\begin{array}{l}x^{2}[1]=0.67 \\
p=.42 \\
\varphi=0.07\end{array}$ & $\begin{array}{l}x^{2}[1]=0.34 \\
p=.56 \\
\varphi=0.05\end{array}$ \\
\hline Hip joint & $\begin{array}{l}x^{2}[1]=1.04 \\
p=.31 \\
\varphi=0.09\end{array}$ & $\begin{array}{l}x^{2}[1]=0.63 \\
p=.43 \\
\varphi=0.07\end{array}$ & $\begin{array}{l}x^{2}[1]=0.80 \\
p=.37 \\
\varphi=0.08\end{array}$ & $\begin{array}{l}x^{2}[1]=0.34 \\
p=.56 \\
\varphi=0.05\end{array}$ \\
\hline
\end{tabular}

1 Pearson's chi-squared test (x2) and 2-sided $p$-value together with mean square contingency coefficient (phi coefficient, $\varphi$ ). Significant differences are highlighted in bold ( 2 -sided $p$-value $<.05$ ) 
Table 7 Differences between strictly religious and less religious students in willingness to be examined

\begin{tabular}{|c|c|c|c|c|}
\hline Religiousness & Same gender student & Different gender student & Same gender tutor & Different gender tutor \\
\hline Head and neck & $\begin{array}{l}x^{2}[1]=0.12 \\
p=.73 \\
\varphi=0.03\end{array}$ & $\begin{array}{l}\mathrm{X}^{2(1)}=12.99 \\
p<.001 \\
\varphi=0.34\end{array}$ & $\begin{array}{l}\mathrm{x}^{2(1)}=6.53 \\
p=.01 \\
\varphi=0.24\end{array}$ & $\begin{array}{l}\mathrm{x}^{2(1)}=6.28 \\
p=.01 \\
\varphi=0.24\end{array}$ \\
\hline Hand & $\begin{array}{l}x^{2}[1]=0.12 \\
p=.73 \\
\varphi=0.03\end{array}$ & $\begin{array}{l}x^{2}[1]=0.25 \\
p=.62 \\
\varphi=0.05\end{array}$ & $\begin{array}{l}x^{2}[1]=1.60 \\
p=.21 \\
\varphi=0.12\end{array}$ & $\begin{array}{l}x^{2}[1]=0.45 \\
p=.51 \\
\varphi=0.06\end{array}$ \\
\hline Arm and shoulder & $\begin{array}{l}x^{2}[1]=0.25 \\
p=.62 \\
\varphi=0.05\end{array}$ & $\begin{array}{l}\mathrm{X}^{2(1)}=20.30 \\
p<.001 \\
\varphi=0.43\end{array}$ & $\begin{array}{l}\mathrm{X}^{2(1)}=9.98 \\
p<.01 \\
\varphi=0.30\end{array}$ & $\begin{array}{l}x^{2(1)}=13.57 \\
p<.001 \\
\varphi=0.35\end{array}$ \\
\hline Upper body & $\begin{array}{l}\mathrm{X}^{2(1)}=11.52 \\
p<.01 \\
\varphi=0.32\end{array}$ & $\begin{array}{l}\mathrm{X}^{2(1)}=14.59 \\
p<.001 \\
\varphi=0.36\end{array}$ & $\begin{array}{l}\mathrm{X}^{2(1)}=8.30 \\
p<.01 \\
\varphi=0.26\end{array}$ & $\begin{array}{l}\mathrm{x}^{2(1)}=6.88 \\
p=.01 \\
\varphi=0.25\end{array}$ \\
\hline Breast & $\begin{array}{l}x^{2(1)}=6.88 \\
p=.01 \\
\varphi=0.25\end{array}$ & $\begin{array}{l}x^{2}[1]=3.06 \\
p=.08 \\
\varphi=0.17\end{array}$ & $\begin{array}{l}x^{2}[1]=2.47 \\
p=.12 \\
\varphi=0.15\end{array}$ & $\begin{array}{l}x^{2}[1]=2.26 \\
p=.13 \\
\varphi=0.14\end{array}$ \\
\hline Abdomen & $\begin{array}{l}x^{2(1)}=17.30 \\
p<.001 \\
\varphi=0.40\end{array}$ & $\begin{array}{l}X^{2(1)}=21.29 \\
p<.001 \\
\varphi=0.44\end{array}$ & $\begin{array}{l}\mathrm{X}^{2(1)}=9.17 \\
p<.01 \\
\varphi=0.29\end{array}$ & $\begin{array}{l}X^{2(1)}=12.90 \\
p<.001 \\
\varphi=0.34\end{array}$ \\
\hline Back & $\begin{array}{l}x^{2(1)}=11.34 \\
p<.01 \\
\varphi=0.32\end{array}$ & $\begin{array}{l}X^{2(1)}=24.90 \\
p<.001 \\
\varphi=0.48\end{array}$ & $\begin{array}{l}X^{2(1)}=12.30 \\
p<.001 \\
\varphi=0.33\end{array}$ & $\begin{array}{l}X^{2(1)}=17.05 \\
p<.001 \\
\varphi=0.39\end{array}$ \\
\hline Groin & $\begin{array}{l}\mathrm{X}^{2(1)}=9.21 \\
p<.01 \\
\varphi=0.29\end{array}$ & $\begin{array}{l}\mathrm{x}^{2(1)}=5.63 \\
p=.02 \\
\varphi=0.23\end{array}$ & $\begin{array}{l}\mathrm{X}^{2(1)}=5.67 \\
p=.02 \\
\varphi=0.23\end{array}$ & $\begin{array}{l}x^{2(1)}=5.08 \\
p=.02 \\
\varphi=0.22\end{array}$ \\
\hline Lower leg and foot & $\begin{array}{l}x^{2}[1]=1.76 \\
p=.18 \\
\varphi=0.13\end{array}$ & $\begin{array}{l}X^{2(1)}=22.85 \\
p<.001 \\
\varphi=0.46\end{array}$ & $\begin{array}{l}x^{2(1)}=15.12 \\
p<.001 \\
\varphi=0.37\end{array}$ & $\begin{array}{l}X^{2(1)}=18.95 \\
p<.001 \\
\varphi=0.42\end{array}$ \\
\hline Knee & $\begin{array}{l}x^{2}[1]=3.20 \\
p=.07 \\
\varphi=0.17\end{array}$ & $\begin{array}{l}\mathrm{X}^{2(1)}=36.46 \\
p<.001 \\
\varphi=0.58\end{array}$ & $\begin{array}{l}X^{2(1)}=20.30 \\
p<.001 \\
\varphi=0.43\end{array}$ & $\begin{array}{l}x^{2(1)}=31.02 \\
p<.001 \\
\varphi=0.53\end{array}$ \\
\hline Hip joint & $\begin{array}{l}X^{2(1)}=23.00 \\
p<.001 \\
\varphi=0.46\end{array}$ & $\begin{array}{l}X^{2(1)}=10.54 \\
p<.01 \\
\varphi=0.31\end{array}$ & $\begin{array}{l}x^{2(1)}=13.82 \\
p<.001 \\
\varphi=0.35\end{array}$ & $\begin{array}{l}\chi^{2(1)}=12.26 \\
p<.001 \\
\varphi=0.33\end{array}$ \\
\hline
\end{tabular}

Pearson's chi-squared test $\left(x^{2}\right)$ and 2-sided $p$-value together with mean square contingency coefficient (phi coefficient, $\varphi$ ). Significant differences are highlighted in bold (2-sided $p$-value $<.05)$

cultures examinations of other parts of the body, e.g. eye, ear, nose and throat, might also be considered as intimate.

Surprisingly, BMI had no relevant effect on the willingness to be examined. Although self-reported BMI tends to be biased [20], we think that for the purposes of this study, two clearly divergent groups were investigated.

In the past, medical students learned examination of intimate body regions by examining patients under general anaesthesia, sometimes without the patients' knowledge or consent [21]. Many physicians performed surgery under the assumption that patients had actually given or implied their consent to such examinations by coming to a teaching hospital. Others believe that patients will not consent if asked, making unauthorized training procedures necessary [22]. In contrast, many patients say that they would be willing to undergo pelvic examinations by medical students if asked $[23,24]$. In the UK, the U.S. and Canada $37-46 \%$ of medical students learned to perform pelvic exams using unconscious patients awaiting surgery [25]. The guidelines of the Joint Commission on Accreditation of Health Care
Organizations state that "participation by patients in clinical training programs should be voluntary" [26]. The Association of American Medical Colleges (AAMC) issued a press release in 2003 that called the use of women under anaesthesia without their knowledge and approval "unethical and unacceptable" [27].

A solution must be found to close this gap in the training of future physicians. Indeed, some people volunteer to become "professional patients", placing their body at the disposal of medical students so that they can learn how to examine intimate parts [28]. So-called gynaecology teaching associates are used in the United States, Canada, Australia, and Scandinavia [25, 29, 30]. Hendrickx et al. conclude that working with intimate examination assistants represents a benefit in medical education by lowering the student's threshold to perform physical examination on both genders [28].

Peer physical examination is a method which enables medical students to improve their skills by using each other as models. It helps them to become familiar with 
techniques before they see real patients in clinical settings [31]. However, 25\% have difficulties and set limits with classmates [31]. Some of our students stated that they feared inappropriate behaviour by their classmates. They felt exposed when undressed as an examination model in front of a group of peers [31]. Abraham et al. point out that clear, direct communication about expectations regarding behaviour and the concepts of professionalism may help to improve classmate behaviour [32]. Direct attention to this issue in the tutorial setting might improve peer-group communication and minimise discomfort. To overcome the issue of being examined by a fellow student, we asked about the willingness to be examined by a student or by a professional tutor in front of the group. However, this did not lead to a higher acceptance. On the contrary, we found a general tendency towards less acceptance of professional tutors. Students are less willing to be examined by a tutor in front of the class than by a peer in a smaller group. We therefore recommend that this technique should not be performed in front of the whole class, but rather in small groups. In the free text area students wrote that they prefer learning new skills in a "safe" environment before being in contact with real patients. Wearn et al. state that peer examination helps to specify skills, allowing students more time to persist or repeat the examination until they "get it right", reducing the potential harm caused to patients [11]. Generally, it has to be taken in account, that learning what is "normal" by examining healthy students is helpful before examining patients with abnormal findings [19]. Our students expect well-prepared tutors, who should repeat some theoretical knowledge at the beginning, demonstrate the examination and serve as supervisor.

Overall, we have shown, similarly to other studies, that students value the opportunity to learn basic skills by examining fellow students. Almost all (98\%) agreed that peer physical examinations are appropriate, valuable, and a comfortable experience [31]. There was a high rating for the importance and motivation to take part. Our students focused on the benefits of learning these skills in a "safe" environment before being in contact with real patients. As time goes by, students' opinions and attitudes have changed, and statements like those found by $\mathrm{O}^{\prime}$ Neill et al. were not found in our group. Students in O'Neill's study cited the free availability of patients as a reason against students learning on one another and expressed the view that examination of normal people was artificial and irrelevant to students' learning needs [19].

Further studies are desirable, investigating larger study populations to elucidate the role of possible confounders in detail, e.g. by use of multivariate analysis. Furthermore, it should be investigated whether particularly strongly religious students were likewise less willing to examine other students as being examined themselves.

\section{Conclusions}

While motivation and acceptance of the physical examination skills course appears to be high, willingness to participate in peer physical examination is rather low for specific regions of the body. Critical regions are especially the breast and groin, followed by the upper body and hip. While gender certainly has an impact, the degree of religiousness in particular seems to influence a student's propensity to volunteer for examination. Most students would prefer to choose their team for physical examination courses themselves rather than be assigned to a group, even if it is a same gender group. This study identified critical body regions for which self-selected groups or simulated patients might be an option. Students point out that small groups, a short revision of the most important theoretical knowledge at the beginning, a well-prepared tutor and structured feedback from the tutor are the basis for a good clinical skills course.

\section{Acknowledgments \\ The authors thank Prof. Dr. Christian Waydhas for assistance in planning the study. We thank Matthias Heue for help with data collection.}

\section{Funding}

The study was financed by means of the University Hospital Essen. We acknowledge support by the Open Access Publication Fund of the University of Duisburg-Essen.

\section{Availability of data and materials}

The datasets used and/or analyzed during the current study are available from the corresponding author on reasonable request.

\section{Authors' contributions \\ $\mathrm{MB}$ analyzed and interpreted the data and wrote the manuscript. JK analyzed the data and was a major contributor in writing the manuscript. AW, SB and SH contributed to data acquisition and revision of the manuscript. $M J$ and $M D$ reviewed the literature and critically revised the manuscript. MDK conceived and supervised the conduct of the study. All authors read and approved the final manuscript.}

Ethics approval and consent to participate

The study was approved by the local ethics committee of the University Hospital Essen (study number: 11-4891-BO) and all participants gave written informed consent.

Consent for publication

Not applicable.

\section{Competing interests}

The authors declare that they have no competing interests.

\section{Publisher's Note}

Springer Nature remains neutral with regard to jurisdictional claims in published maps and institutional affiliations.

\section{Author details}

'Department of Orthopaedics and Trauma Surgery, University Hospital Essen, University of Duisburg-Essen, Hufelandstr. 55, 45147 Essen, Germany. ${ }^{2}$ Department of Otorhinolaryngology, University Hospital Duesseldorf, Heinrich Heine University Duesseldorf, Duesseldorf, Germany. 
Received: 12 June 2018 Accepted: 18 October 2018

Published online: 29 October 2018

\section{References}

1. Kern DC, Parrino TA, Korst DR. The lasting value of clinical skills. JAMA. 1985; 254(1):70-6.

2. Fagan MJ, Griffith RA, Obbard L, O'Connor CJ. Improving the physical diagnosis skills of third-year medical students: a controlled trial of a literature-based curriculum. J Gen Intern Med. 2003;18(8):652-5.

3. Dent JA. Current trends and future implications in the developing role of clinical skills centres. Med Teach. 2001;23(5):483-9.

4. Glaspie HW, Oshiro Wong CM. A discrete system simulation study in scheduling and resource allocation for the John A. Burns school of medicine clinical skills center. Hawaii J Med Public Health. 2015;74(3):87-92.

5. Burg G, French LE. The age of Gutenberg is over: a consideration of medical education--past, present and future. Hautarzt. 2012;63(Suppl 1):38-44.

6. Crossley J, Jolly B. Making sense of work-based assessment: ask the right questions, in the right way, about the right things, of the right people. Med Educ. 2012;46(1):28-37.

7. Rogausch A, Beyeler C, Montagne S, Jucker-Kupper P, Berendonk C, Huwendiek S, et al. The influence of students' prior clinical skills and context characteristics on mini-CEX scores in clerkships--a multilevel analysis. BMC Med Educ. 2015;15:208.

8. Prince KJ, Boshuizen HP, van der Vleuten CP, Scherpbier AJ. Students' opinions about their preparation for clinical practice. Med Educ. 2005;39(7):704-12.

9. Mounsey AL, Bovbjerg V, White L, Gazewood J. Do students develop better motivational interviewing skills through role-play with standardised patients or with student colleagues? Med Educ. 2006;40(8):775-80.

10. Outram S, Nair BR. Peer physical examination: time to revisit? Med J Aust. 2008;189(5):274-6.

11. Wearn A, Bhoopatkar H. Evaluation of consent for peer physical examination: students reflect on their clinical skills learning experience. Med Educ. 2006:40(10):957-64

12. Hendry GJ. Barriers to undergraduate peer-physical examination of the lower limb in the health sciences and strategies to improve inclusion: a review. Adv Health Sci Educ Theory Pract. 2013;18(4):807-15.

13. Delany C, Frawley $\mathrm{H}$. We need a new model for obtaining students' consent to conduct peer physical examinations. Acad Med. 2011;86(5):539 author reply.

14. Pols J, Boendermaker PM, Muntinghe $\mathrm{H}$. Incidence of and sequels to medical problems discovered in medical students during study-related activities. Med Educ. 2003;37(10):889-94.

15. Intimate examinations and chaperones: Guidance: General Medical Council; 2013 [Available from: https://www.gmc-uk.org/ethical-guidance/ethicalguidance-for-doctors/intimate-examinations-and-chaperones.

16. Rees CE, Wearn AM, Vnuk AK, Sato TJ. Medical students' attitudes towards peer physical examination: findings from an international cross-sectional and longitudinal study. Adv Health Sci Educ Theory Pract. 2009;14(1):103-21.

17. Rees CE, Bradley P, Collett T, McLachlan JC. "Over my dead body?": the influence of demographics on students' willingness to participate in peer physical examination. Med Teach. 2005:27(7):599-605.

18. Rees CE, Bradley P, McLachlan JC. Exploring medical students' attitudes towards peer physical examination. Med Teach. 2004;26(1):86-8.

19. O'Neill PA, Larcombe C, Duffy K, Dorman TL. Medical students' willingness and reactions to learning basic skills through examining fellow students. Medical Teacher. 1998;20(5):433-7.

20. Drieskens S, Demarest S, Bel S, De Ridder K, Tafforeau J. Correction of selfreported BMI based on objective measurements: a Belgian experience. Arch Public Health. 2018;76:10.

21. Wilson RF. Autonomy suspended: using female patients to teach intimate exams without their knowledge or consent. J Health Care Law Policy. 2005; 8(2):240-63.

22. Lawton FG, Redman CW, Luesley DM. Patient consent for gynaecological examination. Br J Hosp Med. 1990:44(5):326 9.

23. Ubel PA, Silver-lsenstadt A. Are patients willing to participate in medical education? J Clin Ethics. 2000;11(3):230-5

24. Bibby J, Boyd N, Redman CW, Luesley DM. Consent for vaginal examination by students on anaesthetised patients. Lancet. 1988;2(8620):1150.

25. Abraham S. Vaginal and speculum examination in medical curricula. Aust N Z J Obstet Gynaecol. 1995;35(1):56-60.

26. Association CoEaJAotAM. Medical students' involvement in patient care Clin Ethics. 2001;12(2):111-5.
27. AAMC Statement on Patient Rights and Medical Training (June 12, 2003) [press release]. 06/12/2003 2003.

28. Hendrickx K, De Winter BY, Wyndaele JJ, Tjalma WA, Debaene L, Selleslags B, et al. Intimate examination teaching with volunteers: implementation and assessment at the University of Antwerp. Patient Educ Couns. 2006;63(1-2): 47-54.

29. Beckmann CR, Spellacy WN, Yonke A, Barzansky B, Cunningham RP. Initial instruction in the pelvic examination in the United States and Canada, 1983 Am J Obstet Gynecol. 1985;151(1):58-60.

30. Wijma B. Gynecologic examination, a role-playing for two. Lakartidningen. 1998:95(11):1125-9.

31. Chang EH, Power DV. Are medical students comfortable with practicing physical examinations on each other? Acad Med. 2000;75(4):384-9.

32. Abraham $\mathrm{S}$. The effect of sexual experience on the attitudes of medical students to learning gynecological examinations. J Psychosom Obstet Gynaecol. 1996;17(1):15-20.
Ready to submit your research? Choose BMC and benefit from:

- fast, convenient online submission

- thorough peer review by experienced researchers in your field

- rapid publication on acceptance

- support for research data, including large and complex data types

- gold Open Access which fosters wider collaboration and increased citations

- maximum visibility for your research: over $100 \mathrm{M}$ website views per year

At $\mathrm{BMC}$, research is always in progress.

Learn more biomedcentral.com/submissions 